\title{
Intrauterine unilateral single inferior accessory renal artery: a case report
}

\author{
Punya Pratap Singh ${ }^{1 *}$, Gahlot Kavita ${ }^{2}$
}

\begin{abstract}
${ }^{1}$ Department of Radiodiagnosis, Budelkhand Medical College, Sagar, Madhya Pradesh, India
${ }^{2}$ Department of Obstetrics and Gynaecology, Bhagyodaya Tirth Charitable Trust Super - Speciality Hospital, Sagar, Madhya Pradesh, India
\end{abstract}

Received: 21 February 2019

Accepted: 01 April 2019

\section{*Correspondence:}

Dr. Punya Pratap Singh,

E-mail: drpunya@gmail.com

Copyright: () the author(s), publisher and licensee Medip Academy. This is an open-access article distributed under the terms of the Creative Commons Attribution Non-Commercial License, which permits unrestricted non-commercial use, distribution, and reproduction in any medium, provided the original work is properly cited.

\begin{abstract}
In comparison with other organs, variants of blood supply to the kidneys were always at special attention due to end arteries. Anatomic variations in the renal vasculature are common and occurrence is varying in between $25 \%$ to $40 \%$. The most common variation is presence of accessory renal arteries. Accessory renal artery generally diagnosed on abdomen angiography studies or cadaveric dissection. Only few studies or case report of intrauterine detection of accessory renal artery are available in printed and online literature. During a dedicated anomaly scan of 23 week foetus, detection of an accessory renal artery on left side entering kidney in inferior pole courses parallel to main renal arteries and arising from abdominal aorta. Knowledge of the possible anatomic variations and anomalies of the renal arteries like accessory renal arteries are necessary for proper surgical management during renal transplantation, abdominal aorta aneurysm repair, different urological procedures and angiographic procedures. As the various type of vascular and non - vascular interventions increase, knowledge of the different type of variations of the renal arteries is necessary for proper surgical management in the different specialties.
\end{abstract}

Keywords: Accessory renal artery, Abdominal aorta, Intrauterine, Inferior polar artery

\section{INTRODUCTION}

In comparison with other organs, variants of blood supply to the kidneys were always at special attention due to end arteries. ${ }^{1}$ The most common variation is presence of accessory renal arteries. ${ }^{2}$ As the various type of vascular and non - vascular interventions increase, knowledge of the different type of variations of the renal arteries is necessary for proper surgical management in the different specialties. $^{3}$ The earliest record about accessory renal arteries seem to be that of Eustachius made in 1552 on copper plates, which were published in 1714 by Lancisi. $^{4,5}$ According to Graves, any artery arising from the aorta in addition to the main renal artery should be named 'accessory' and the renal arteries arising from sources other than the aorta should be called 'aberrant'. 6
Anatomic variations in the renal vasculature are common, occurring in $25 \%$ to $40 \%$ of kidneys. The most common variation is presence of accessory renal arteries. One or two accessory renal arteries frequently occur, especially on the left and more common fron above main renal artery. They usually enter above or below the renal hilum. Lower pole arteries on either side can cross anterior to the collecting system, causing obstruction at the uretero - pelvic junction. ${ }^{7}$ On the right side, the lower pole arteries usually also cross anterior to the inferior vena cava. ${ }^{8}$

The accessory renal artery variations can be explained in the light of embryonic development from the lateral mesonephric branches of the dorsal aorta and its molecular regulation. 
Accessory renal artery generally diagnosed on abdomen angiography studies or cadaveric dissection. Only few studies or case report of intrauterine detection of accessory renal artery are available in printed and online literature. Hence this case with a rare presentation is being presented here.

\section{CASE REPORT}

A 31-year-old primigravida with 23 weeks of gestation came for detailed anomaly scan. She is not a known case of hypertension or diabetes mellitus or asthama. Nonreactive for TORCH group of infections.

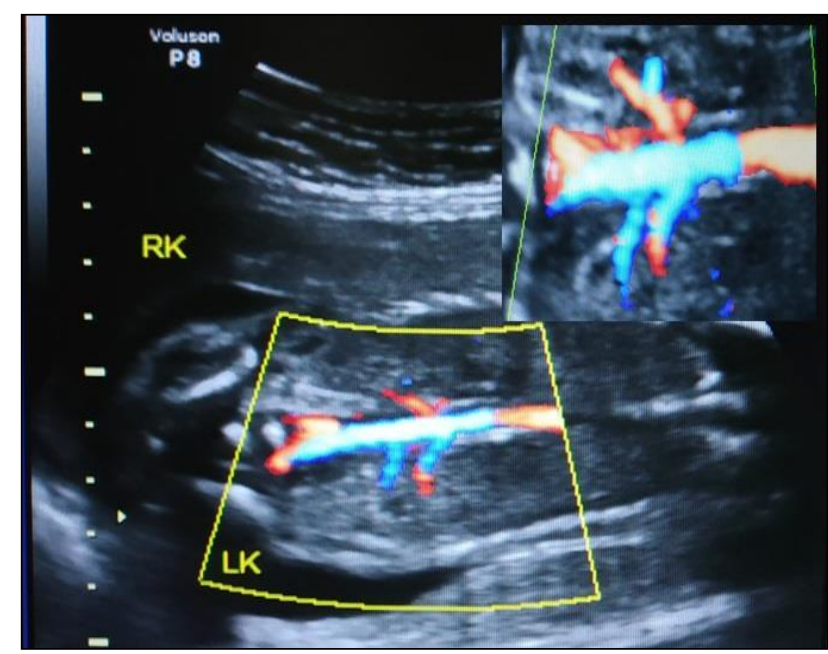

Figure 1: Colour Doppler image of foetal abdomen, an inferior accessory renal artery supplying lower pole of left kidney. However, right side normal single renal artery noted.

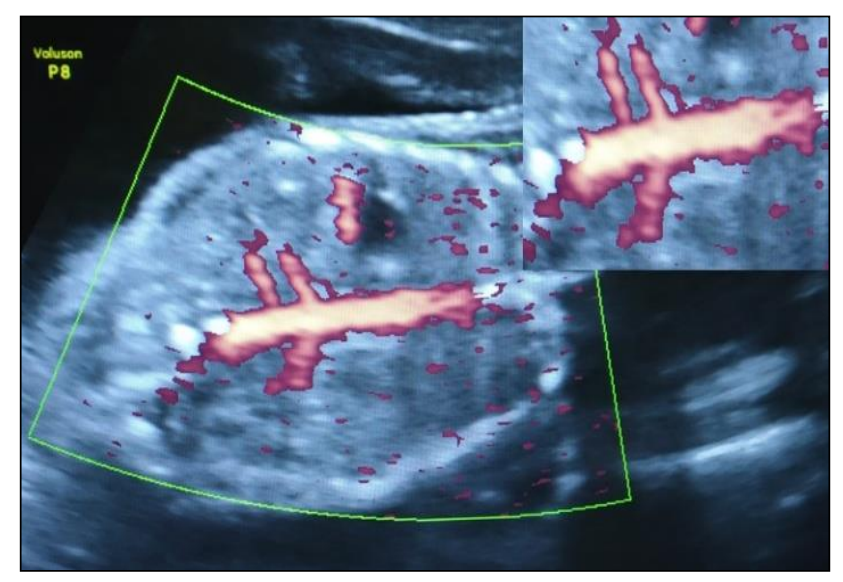

Figure 2: Power Doppler image of foetal abdomen is showing an inferior accessory renal artery supplying lower pole of left kidney.

During anomaly scan conducted via GE Voluson P8 with 3D/4D probe and using all Doppler modes - colour doppler, HD flow and power doppler mode, an accessory renal artery noted on left side entering left kidney in inferior pole below renal pelvis courses parallel to main renal arteries and arising from abdominal aorta suggestive of unilateral left side inferior accessory renal artery. There is no accompanying accessory renal vein noted. However, no variations were found in the renal artery on right side. Mild pyelectasis with distended urinary bladder noted early part of scan which becomes normal on foetal urination in lateral part of scan. On fallow up on next day, no foetal pyelectasis noted.

\section{DISCUSSION}

The earliest record about accessory renal arteries seem to be that of Eustachius made in 1552 on copper plates, which were published in 1714 by Lancisi. ${ }^{4,5}$ Accessory renal artery generally diagnosed on abdomen angiography studies or cadaveric dissection. Multiple publications are available in anatomy and other medical journals about accessory renal arteries in extra - uterine period means after birth. Limited literature available about intrauterine detection of accessory renal artery.

Cicekcibasi AE et al, investigated the origin, localizations and anatomic variations of the renal artery (RA) in human fetuses. In total, 90 fetuses of spontaneous abortion (45 males, 45 females) with no congenital malformations were included in the study. ${ }^{9}$ There were no variations in $75 \%$ of the cases whereas the remaining $25 \%$ had several variation patterns. The presented morphological results are as follows: a single hilar artery in $75 \%$ of the cases, double hilar arteries in $11.1 \%$, an inferior polar artery in $10.5 \%$, and a superior polar artery in $3.3 \%$ of specimens studied.

Degani S et al, in their study of 120 fetuses, 117 fetuses were showing a single renal artery originating from each side of the abdominal aorta. ${ }^{10}$ The origin of the right renal artery from the abdominal aorta was superior to, at the same level as, and inferior to that of the left renal artery in $47 \%(55 / 117), 25.5 \%(30 / 117)$, and $27.5 \%(32 / 117)$ of the cases, respectively. An accessory right RA was found in 3 cases. Bifurcation of the right renal artery was found in 2 cases. There were no variations of the origin of renal vessels in $83 / 120$ cases $(69 \%)$, whereas the remaining $37 / 120(31 \%)$ had or several variation patterns. Variations in renal vessels were found in 8 of the 12 fetuses with renal malformations: accessory artery in 3 cases, origin of the right renal artery from the iliac artery in horseshoe kidney and in 2 cases with pelvic kidney, and bifurcation in 2 of the fetuses with double collecting system.

Bazelmans $M$ et al, also observed two normal kidneys with bilateral accessory renal arteries in a fetus at 26 weeks' gestation using Three-dimensional power Doppler analyzed in 4 -dimensional view and by use of a virtual reality system to render images in the Barco I-space. ${ }^{11}$

Accessory renal arteries are common $(30 \%$ of individuals), and usually arise from the aorta above or below the main renal artery and follow it to the renal 
hilum. The lower renal segment is more frequently fed by an accessory vessel. Two or more renal arteries are more common on the left side. Accessory renal arteries are regarded as persistent embryonic lateral splanchnic arteries. Accessory vessels to the inferior pole cross anterior to the ureter and may, by obstructing the ureter, cause hydronephrosis. Rarely, accessory renal arteries arise from the coeliac or superior mesenteric arteries near the aortic bifurcation or from the common iliac arteries. The main importance of the abnormality is as a source of potential error during operations in the retroperitoneum. The renal arteries are functional end-arteries, so division or blocking of an aberrant / accessory lower pole artery leads to infarction of the section of renal parenchyma supplied aberrant / accessory renal artery. ${ }^{12}$

Ozkan et al, in his angiographic evaluation of origin and variation of renal arteries (163 females and 692 males), found renal arteries originating between the first and second lumbar vertebral level in most patients. ${ }^{13}$ Variations of renal arteries included multiple arteries (24\%), bilateral multiple arteries (5\%), and early division $(8 \%)$ of cases. Additional renal arteries on the right side were more common the left side (Right - 16\% and Left $13 \%$ ) of cases. This result should be kept in mind when a non-invasive diagnostic search is performed for renal artery stenosis or when renal surgery related to renal arteries is performed. ${ }^{13}$

Presence of bilateral accessory renal arteries can be explained in the light of embryogenic development and its molecular regulation. Each primitive dorsal aorta gives off ventral splanchnic arteries, lateral splanchnic arteries, somatic arteries and caudal continuation. The lateral splanchnic arteries supply, on either side, the mesonephros, metanephros, the testis or ovary and the suprarenal gland.

All these mentioned structures develop, either in whole or in part, from the intermediate mesenchyme of the mesonephric ridge. One testicular or ovarian artery and three suparenal arteries persist on each side. Additional renal arteries are frequently present and may be looked on as branches of persistent Lateral splanchnic arteries. ${ }^{8}$

The earlier classification given by American urology association meeting at St. Louis, Peris June 1910 of accessory renal arteries which most frequently occur is as follows: ${ }^{14}$

Type 1: Two separate renal arteries arise from the side of the aorta to supply the kidney. The two arteries enter the hilum of the kidney dividing, in to two or more branches. This variety may be called the two-artery type.

Type 2: A main renal artery arises from the aorta in the normal manner, but a second accessory, artery arises from the aorta a variable distance away, passing directly from the aorta to the upper pole of the kidney. This may be called the superior polar type.
Type 3: The main renal artery arises from the side of the aorta and passes to the hilum in the normal manner. An accessory renal artery arising separately from the aorta a variable distance from the main trunk passes to the lower pole of the kidney. This is called the inferior polar type.

Type 4: Three renal arteries arise from the side of the aorta and pass separately to the hilum of the kidney. This is called the three-artery type.

Type 5: Four renal arteries arise from the aorta and pass separately to the hilum. This is called the four-artery type.

Type 6: The accessory artery arises from the common, external or internal iliac, rarely from the hepatic, middle sacral, spermatic and inferior phrenic, lumbar or even pancreatic or colonic arteries. This may be called the extra-aortic accessory type, and is quite rare as compared to the previously described types.

Type 7: Superior or inferior polar arteries arise from a single normal renal artery before it enters the kidney.

There are other classifications of supernumerary renal arteries by Merklin and Michels classification for accessory arteries (based on their origin and entry into the kidney). ${ }^{15}$ There are three types and they are as follows:

- $\quad$ Type - 1: Supernumerary renal arteries originating from the aorta.

- $\quad$ Type - 2: Supernumerary renal arteries originating from main renal arteries.

- Type - 3: Supernumerary renal arteries that can come from other sources.

Present case is of Type-3 (Inferior polar type) as per American urology association classification and of Type1 according to Merkling and Michel classifications.

\section{CONCLUSION}

Knowledge and awareness of all possible anatomic variations and anomalies of the renal arteries like presence of accessory renal arteries are necessary for proper surgical management during renal surgeries like transplantation, repair of abdominal aorta aneurysm specially involving or reaching up to origin of renal arteries, different urological procedures and angiographic interventions. As number of invasive interventions such as renal transplantation, interventional radiologic procedures and urologic operations increases, awareness of the all possible variations of the renal arteries are necessary for proper surgical management.

\section{ACKNOWLEDGMENTS}

Authors would like to thank Mr. Rajesh Maurya, Dr. Nidhi Mishra, Dr. Sona Singh, Dr. Nagendra Singh, Dr. Mahipal Singh and Dr. Priyank Jain for helping us in 
every step of research work. We also acknowledge Dr. Somshankar Pandy and Dr. Vreshbhan Ahirvar for her assistance with the radiologic findings and $\mathrm{Mr}$. Indal Singh for his assistance in statistics work. Mr. Shri Jalim Singh, Smt. Pushpa Singh, Smt. Pooja Singh, Mr. Narendra Yadav, Mr. Rahul Shrivastava and Mr. Ravikant Gupta for mental support and technical help during study.

Funding: No funding sources

Conflict of interest: None declared

Ethical approval: Not required

\section{REFERENCES}

1. Covantev S, Mazuruc N, Belic O. Renal Arteries: A morphological and angiographic assessment. Online J Health Allied Scs. 2018;17(2):9.

2. Wein AJ, Kavoussi LR, Novick AC. CampbellWalsh Urology. In: Stuart B (ed), Anomalies of the Upper Urinary Tract. 9th edn. Saunders Elsevier, Philadelphia. 2007;263-266.

3. Patasi B, Boozary A. A case report: accessory right renal artery.International Journal of Anatomical Variations 2: 2009;119-21.

4. Eustachius B. The aberrant renal arteries. J Anat. 1552;90:553-8.

5. Lancisi. An unusual anomalous blood vessel connecting the renal and internal spermatic arteries. Anatomical Record. 1714;102:205-10.

6. Graves FT. The aberrant renal artery. J Anat. 1956;90:553-8.

7. Williams PL, Bannister LK, Berry MM. Gray's Anatomy. In: Gabella G(ed),Cardiovascular system.38th edn. Edinburgh, Churchill Livingstone. 1995;1556-7.

8. Standring S. Ellis H, Healy JC, Johnson D, Williams A. Gray's Anatomy. 39th Edition Philadelphia Elsevier Churchill Livingstone. 2005;1274:1042.
9. Cicekcibasi AE. An investigation of the origin, location and variations of the renal arteries in human fetuses and their clinical relevance, Annals of Anatomy - Anatomischer Anzeiger. 2005;4(1):421-7.

10. Degani S, Leibovitz Z, Shapiro I, Ohel G. Variations of the origin of renal arteries in the fetus identified on power Doppler and 3D sonography. J Clin Ultrasound. 2010;38(2):59-65.

11. Bazelmans M, Peters NCJ, Koning AH, Eggink AJ, Cohen OTE. Power doppler rendering of fetal bilateral accessory renal arteries in virtual reality. Ultrasound Obstet Gynecol. 2014;44:375-6.

12. Mir NS. Bilateral duplication of renal vessels: anatomical, medical and surgical perspective. Int $\mathbf{J}$ Health Sci (Qassim). 2008;2(2):179-85.

13. Ozkan U, Oğuzkurt L, Tercan F, Kizilkiliç O, Koç Z, Koca N. Renal artery origins and variations: angiographic evaluation of 855 consecutive patients. Diagn Interv Radiol. 2006;12(4):183-6.

14. Daniel N, Eisendranath, David C. The surgical importance of accessory renal arteries. Association, American Urological. Transactions. Reprint. London: Forgotten Books. 2013;174-5.

15. Merklin RJ, Michels NA. The variant renal and suprarenal blood supply with data on the inferior phrenic, ureteral and gonadal arteries: a statistical analysis based on 185 dissections and review of the literature. J Int Col Surg. 1958;29(1):41-76.

16. Patasi B, Boozary A. A case report: accessory right renal artery. Int J Anat Variat. 2009;2:119-21.

Cite this article as: Singh PP, Kavita G. Intrauterine unilateral single inferior accessory renal artery: a case report. Int J Reprod Contracept Obstet Gynecol 2019;8:2118-21. 